\title{
PERCEPÇÕES DE DOCENTES ACERCA DOS CONCEITOS DE LÍNGUA E DE CULTURA NO ENSINO DE INGLÊS ${ }^{1}$
}

\author{
Gisele dos Santos da SILVA \\ Pós-Graduação em Linguística - Universidade Federal do Paraná
}

RESUMO: este artigo é um recorte de minha pesquisa de mestrado em Estudos Linguísticos pelo Programa de Pós-Graduação da Universidade Federal do Paraná e tem por objetivo apresentar a percepção de um grupo de professores a respeito dos conceitos de língua e de cultura e qual a relação de ambos no ensino da língua inglesa no cenário brasileiro atual. Sendo assim, toma-se como referência para a análise estudos pós-modernos sobre cultura (BHABHA, 2013; HALL, 2006, 2013) e a concepção sociointeracionista da linguagem, compreendendo língua como discurso (BAKHTIN, 1995; JORDÃO, 2006) e dialogando com a noção de língua como cultura (KRAMSCH, 1993, 1998). A pesquisa realizada é de cunho qualitativo-interpretativista (BAUER, GASKELL, ALLUM, 2012; BORTONI-RICARDO, 2008), pois considera a interpretação das respostas obtidas de entrevistas e questionários realizados com um grupo de professores. O grupo fora composto por um total de 6 docentes, todos recém egressos do curso de Licenciatura em Letras da Universidade Tecnológica Federal do Paraná e em atuação no ensino da língua inglesa em instituições da região de Curitiba. Por meio de análise de conteúdo (BAUER, 2012), os dados foram codificados e categorizados para a perquirição dos entendimentos sobre ambos os conceitos por parte dos docentes. Entre os resultados observados, destaca-se a constante percepção da indissociabilidade das noções de língua e de cultura corroborando a acepção de língua como cultura, como propõe Kramsch $(1993,1998)$, no processo de ensino-aprendizagem de inglês. PALAVRAS-CHAVE: percepções; cultura; ensino de língua inglesa.

ABSTRACT: this paper is part of my master thesis in Linguistic Studies by the postgraduate program at the Federal University of Paraná. It aims to present the perception from a group of teachers about the conceptions of language and culture, and the relation of both in English language teaching in Brazil nowadays. Therefore, as references for this research, it was considered some post-modern studies about culture (BHABHA, 2013; HALL, 2006, 2013) and the social interactionist conception of language which comprehends language as discourse (BAKHTIN, 1995; JORDÃO, 2006), and it also interact with the notion of language as culture (KRAMSCH, 1993, 1998). This is a qualitative-interpretative research (BAUER, GASKELL, ALLUM, 2012; BORTONI-RICARDO, 2008) since it considers the interpretation of some answers from interviews and questionnaires made with a group of teachers. This group was composed by a total of six teachers; all of them were majored in Languages (Portuguese and English) at Federal University of Technology of Paraná, and they were teaching English in institutions in Curitiba city. The data were codified and categorized through content analysis (BAUER, 2012) to verify the understandings about both conceptions according to teachers. As results, there is the constantly perception of the connection between the language and the culture notions supporting the idea of language as culture, such as Kramsch $(1993,1998)$ proposed, in English teaching and learning process.

KEYWORDS: perceptions; culture; English language teaching.

\footnotetext{
${ }^{1}$ Este artigo é derivado de minha dissertação de mestrado pela UFPR e foi desenvolvido com o apoio da Coordenação de Aperfeiçoamento de Pessoal de Nível Superior (CAPES) - Brasil.
} 


\section{Introdução}

No ensino de línguas estrangeiras, a relação entre o conceito de cultura e língua costuma ser bastante questionada e discutida, entretanto, esta relação pode não ser muito frequente nas práticas em sala de aula. Há seis anos, quando lecionava português para um grupo de estrangeiros no centro de línguas da Universidade Tecnológica Federal do Paraná, eu e minhas colegas professoras tínhamos a forte percepção da presença e da importância de se trabalhar a cultura brasileira em diferentes contextos enquanto ensinávamos nossa língua., pois nossa cultura adentrava a sala de aula a cada escolha vocabular apresentada, a cada novo tema discutido, a cada questionamento levantado por nossos estudantes. A princípio, parecia muito fácil falar de cultura enquanto ensinávamos o Português Brasileiro, nossa língua materna, assim como nossa cultura. No entanto, percebemos que a relação língua e cultura no ensino de línguas nem sempre é tão constante assim.

Logo depois, ao participar do Programa Institucional de Bolsa de Iniciação à Docência de Língua Inglesa (PIBID) e trabalhar com o inglês na rede pública de ensino, veio-me, novamente, o questionamento de "como a cultura deve ser abordada de modo que não seja compreendida apenas como algo a mais ou como algo que se distancia da língua em si?". Além disso, não queríamos apenas reforçar estereótipos de países anglofalantes. Tendo em vista a perspectiva pós-moderna de que língua e cultura são indissociáveis, surgiram-me alguns questionamentos como "será que os alunos que estudam a língua inglesa também concebem essa relação da língua e da cultura?" ou "como o professor pode mediar essa percepção do aluno sobre a cultura da língua inglesa a cada atividade em sala de aula, sem reforçar estereótipos apenas?". Destes questionamentos e experiências decorreu o interesse em analisar como a cultura é trabalhada e percebida em sala de aula no ensino de línguas estrangeiras e como os professores relacionam estes dois conceitos tão significantes nessa área - cultura e língua.

Este trabalho é parte da pesquisa que deu origem a minha dissertação, que analisa as representações culturais de professores em relação à língua inglesa realizada entre 2014 e 2015 em Curitiba. Desse modo, aqui é feito um recorte tendo como foco o ensino de línguas e a cultura, esta pesquisa foi realizada com o intuito de investigar como professores de língua inglesa em exercício percebem a relação entre língua e cultura no ensino/aprendizagem de inglês. Para isso, um grupo de professores participou da geração de dados respondendo alguns questionamentos em forma de questionário e entrevista. Com os dados obtidos, uma análise de conteúdo foi realizada para verificar as percepções destes docentes sobre o tema proposto.

\section{Língua e cultura enquanto conceitos}

Para viabilizar a análise das percepções acerca dos termos cultura e língua no ensino/aprendizagem de língua inglesa conforme proposto, algumas noções sobre cultura foram revisitadas e discutidas. Dessa maneira, como embasamento teórico desta pesquisa além dos conceitos relativos à cultura, como a noção de comunidades imaginadas e de estereótipos, também abordaremos a concepção pós-estruturalista de língua numa visão bakhtiniana. 
Quando tratamos da questão cultural no ensino, ingressamos em um campo conceitual bastante abrangente e complexo, principalmente no que diz respeito à percepção do termo cultura, uma vez que este pode assumir diferentes perspectivas conforme a área de estudo ou contexto histórico e social em que é utilizado. Sendo assim, retomamos algumas acepções atribuídas ao conceito em diferentes perspectivas e momentos históricos, partindo de uma visão antropológica da palavra cultura até chegar a uma perspectiva pós-moderna desta.

Primeiramente, na visão antropológica, Eagleton (2005) ressalta que cultura é um conceito derivado da natureza, significando originalmente a noção de "lavoura" ou "cultivo agrícola". Nesse contexto, o termo vem de colere, raiz latina, que pode assumir vários sentidos, desde a ideia inicial de cultivar (a natureza) ao mesmo tempo em que pode ser entendido como "habitar", "adorar" ou "proteger". Mas colere ainda origina outro radical sugere o cultivo à natureza, também pode sugerir o cultivo da natureza individual, o cultivo do $\mathrm{Eu}$, ao que Eagleton (2005) se refere como autocultura, ou seja, esta se volta à natureza humana, cultivando e refinando a dualidade existente no interior do indivíduo. Além disso, Eagleton (2005) apresenta três percepções do termo cultura (cultura como civilização, como modo de vida específico e como produção artística) resultantes dos estudos de Raymond Williams, e vai além, ampliando-o conforme sua compreensão e criando o que poderia chamar de uma quarta concepção.

Para o autor, a cultura pode ser comparada a uma percepção da consciência devido a sua incompletude e instabilidade. Com isso, a cultura como modo de vida vai além de simples caracterizações e acaba unindo as pessoas, não sob um viés de homogeneidade cultural, mas heterogeneamente, onde a o entrelaçamento de diferentes pensamentos e ações dentro de um contexto social. Dessa maneira, a cultura se divide em consciente (as representações que se manifestam como imagem de todos ou da maioria das pessoas) e inconsciente (que se refere à minoria). Além disso, o autor defende que enxergamos nossa cultura como uma norma que nos representa e só quando olhamos para o Outro e estabelecemos pontos de comparação, de diferenciações ou de negociações conseguimos perceber a heterogeneidade cultural tanto de nosso próprio contexto quanto do contexto do Outro. Em suma, a cultura para Eagleton (2005) corresponde a todo e qualquer modo de agir, pensar, interagir que seja característico de um grupo social, consciente ou inconscientemente.

Voltando-se para os estudos de Raymond Williams (1992), o autor também ressalta a dificuldade encontrada na tentativa de definição do termo cultura, focando em dois modos possíveis de se entender o termo: no primeiro, a cultura é compreendida como um "espírito formador" de um modo de vida global, isto é, seria uma noção que engloba todo o âmbito das atividades sociais, mas se faz mais evidente em atividades "especificamente culturais" seja, atividades ligadas às artes, à linguagem e a qualquer tipo de trabalho intelectual; já o segundo entendimento enfatiza em "uma ordem social global", em que uma determinada cultura "é considerada produto direto ou indireto de uma ordem primordialmente constituída por outras atividades sociais.”. Segundo Williams (1992, p. 13),

[...] há certa convergência entre (i) os sentidos antropológico e sociológico de cultura como "modo de vida global" distinto, dentro do qual percebe-se, hoje, um "sistema de significações" bem definido não só como essencial, mas como essencialmente envolvido em todas as formas de atividade social, e (ii) o sentido mais especializado, ainda que também mais comum, de cultura como "atividades artísticas e intelectuais", embora estas, devido à

\footnotetext{
${ }^{2}$ Destaque do autor no texto original.
} 
ênfase em um sistema de significações geral, sejam agora definidas de maneira muito mais ampla, de modo a incluir não apenas as artes e as formas de produção intelectual tradicionais, mas também todas as "práticas significativas" - desde a linguagem, passando pelas artes e filosofia, até o jornalismo, moda e publicidade - que agora constituem esse campo complexo e necessariamente extenso.

Tendo em vista os dois sentidos supracitados, cultura pode ser vista como um conceito generalizante ou especializado, ainda que as ideias atribuídas ao termo não sejam totalmente excludentes, já que são percepções que ressignificam a cada momento e contexto.

Sendo assim, a ideia de cultura como um termo multifacetado é reforçada, por isso seus sentidos podem ser negociados conforme as áreas que fazem uso de tal noção e conforme a necessidade de cada contexto. No entanto, Raymond Williams (1992) advoga o conceito de cultura como um sistema de significações, entendendo tal sistema como uma forma de organização social sistemática ou, mais especificamente, como um sistema de sinais ou de signos. Mesmo assim, não são vistos como sistemas totalmente dissociáveis, já que fazem parte de algo mais amplo: um sistema social. O social engloba diversos outros sistemas, dentre eles os sistemas de representações, sendo o sistema social aquele que possibilita diversas negociações para o conceito de cultura,

pois um sistema de significações é inerente a qualquer sistema econômico, a qualquer sistema político, a qualquer sistema geracional e, de modo mais geral, a qualquer sistema social. Contudo, ele pode, também, distinguir-se, na prática, como um sistema em si mesmo: por exemplo, da maneira mais evidente, como uma língua; ou como um sistema de pensamento ou de consciência, ou, para utilizar aquele difícil termo alternativo, uma ideologia; e, ainda, como um conjunto de obras de arte e de pensamento particularmente significativo. Ademais, tudo isso existe não só como instituições e obras, e não só como sistema, mas também como práticas ativas e estados de espírito. (WILLIAMS, 1992, p. 206),

ou seja, na visão de Williams (1992), quando se compreende a cultura como um sistema de significações realizado dentro de uma organização social abre-se espaço para o estudo de várias outras atividades, relações e instituições de maneira significativa.

Para além da noção de cultura como sistema de significações, esta pode ainda ser entendida como comunidades imaginadas. Ao se tratar da cultura de uma nação, por exemplo, várias noções e imagens podem aparecer como determinantes daquilo que seria a representação identitária de um determinado grupo, sendo estes símbolos e representações considerados a cultura nacional desse grupo. Na concepção de Stuart Hall (2006, p. 50), "uma cultura nacional é um discurso", ou seja, é uma maneira de dar sentidos às nossas ações e a nós mesmos enquanto seres sociais. Hall (2006) assegura que as culturas nacionais constroem sentidos referentes à nação e o sujeito pode se identificar com tais sentidos, construindo a sua identidade e a do grupo. Tais sentidos abrangem memórias, histórias e imagens de uma nação ao longo do tempo, formatando sua identidade. Assim, a identidade cultural de uma nação pode ser compreendida como uma comunidade imaginada. Em outras palavras, a ideia de cultura nacional é baseada fortemente em conceitos abstratos, muitas vezes advindos da imaginação das pessoas a respeito de sua nação. Como aponta Kramsch (1998), o contexto sociocultural que delimita a identidade de uma comunidade vai além dos 
níveis sincrônico e diacrônico, integrando também o nível da imaginação. Posto isso, um grupo social compartilha não só uma língua, artefatos e fatos comuns, mas principalmente sonhos, pensamentos e ideais realizados ou imaginados, sendo tais elementos responsáveis pela união das pessoas desse grupo, permitindo a elas se reconhecerem enquanto uma nação por partilharem algo em comum.

Ainda no que tange às comunidades imaginadas, é perceptível a presença de narrativas, de imagens e de pensamentos pré-existentes e difundidos como característicos da identidade de uma nação, ou seja, nas comunidades imaginadas encontramos também os estereótipos culturais. Os estereótipos seriam as generalizações feitas sobre a cultura e o comportamento de um determinado povo como forma de classificá-lo. Em outras palavras, estereótipos é uma espécie de rótulos atribuídos aos membros de cada nação. Por exemplo, alguns estereótipos atribuídos ao Brasil e ao povo brasileiro: o país que ama e joga bem o futebol, país do carnaval e de mulheres bonitas, ou o país onde se dá um "jeitinho" para tudo. Para Kramsch (1998, p. 67), os estereótipos referentes à cultura e à língua de um indivíduo ou de um povo são condicionados pela cultura do Outro, de quem está de fora, a partir de ideias e imagens pré-concebidas em sua própria cultura, portanto estereótipos costumam ser arbitrários e imaginados. Em suma, nossas representações sobre o Outro geralmente são baseadas em narrativas estereotipadas, levando-nos a criar a percepção de uma cultura nacional alheia como comunidade imaginada.

Ainda que a percepção da cultura como comunidade imaginada ou como estereótipo seja bastante frequente, a visão pós-moderna parece tratar da cultura de maneira mais plausível no que diz respeito ao ensino de línguas. O conceito pós-moderno de cultura vai de encontro ao discurso colonialista que entende a cultura como algo praticamente fixo e imutável. O conceito pós-moderno se apresenta relacionado diretamente à ideia da instabilidade, da contingência e da atemporalidade, uma vez que defende a incomensurabilidade cultural em um espaço nacional e/ou internacional. Neste viés, não existem mais fronteiras da cultura local, tornando-a global. A cultura deixa de ser a descrição do modo de vida de um grupo social ou a sistematização deste, e passa a ganhar sentido a cada novo ato enunciativo. A cultura é mista, hibrida e negociável. Segundo Bhabha (2013), na pós-modernidade "a temporalidade não sincrônica das culturas nacional e global abre um espaço - um terceiro espaço - onde a negociação das diferenças incomensuráveis cria uma tensão peculiar às existências fronteiriças." (p. 344). Posto isso, não existe mais um sujeito da cultura centrado, os significados não são mais estáveis e sim provisórios, e a transformação é constante. O mito do colonizador e colonizado é substituído pela ideia de sujeito agente; e as diferenças culturais dão lugar à distância cultural - distâncias negociadas e emancipadas no terceiro espaço.

O terceiro espaço proposto por Bhabha (2013) seria um local conflituoso de negociações de significados em que nenhum sujeito é visto como mais importante que o outro, mas cada um tem sua opinião e vontade de verdade e tentam negociar suas percepções nesse terceiro espaço. Na visão de Bhabha (2013, p.345-346), no espaço pós-moderno não há Uma cultura ou a Outra, mas algo além, ou seja, as antigas diferenças são ressignificadas nesse ambiente hibrido que compõe o terceiro espaço. Portanto, a possibilidade de constante negociação de sentidos e ressignificação nesse espaço misto faz com que a visão pós-moderna de cultura (como culturas, no plural) dialogue com a concepção discursiva de língua e seja, nesta pesquisa, adotada como aquela que melhor se adequa ao ensino de línguas estrangeiras. Vale ressaltar que os conceitos aqui abordados constroem um pequeno panorama dos possíveis entendimentos do termo cultura, não pretendendo esvair todos os conceitos possíveis. 
Assim como a multiplicidade de entendimentos inerentes ao conceito de cultura, várias são as concepções de língua. Entretanto, versaremos apenas sobre a concepção discursiva de língua. Tal concepção, também compreendida como pós-estruturalista, vê a língua enquanto discurso, sendo este uma espécie de lente o sujeito pela qual o sujeito pode interpreta o mundo, significando-o (JORDÃO, 2006). Consoante à acepção pós-moderna de cultura, a perspectiva discursiva de língua propõe que os sentidos não são fixos, mas sim construídos a cada nova situação interacional, e o discurso é dialógico, isto é, sofre influência de outros discursos que circulam no contexto social. Dessa maneira, os sentidos podem e devem ser questionados e ressignificados a cada novo contexto e a linguagem assume o papel importante de construir conhecimento. Dessa forma, a realidade não é uma construção individual do sujeito, pelo contrário, ela é uma construção coletiva e suas interpretações nunca são neutras, pois são estabelecidas culturalmente. Logo, a língua como discurso é um fator social por excelência, dialogando com a visão bakhtiniana em que a língua se efetiva no âmago social a cada interação discursiva. Resumindo, para Bakhtin (1995), o sujeito é um ser social que age e interage em uma determinada esfera social através da linguagem, ou seja, suas ideias se materializam no discurso. Portanto, a língua não é estável e se ressignifica em cada contexto de uso semelhantemente à concepção pós-moderna de cultura.

\section{Metodologia e contexto da pesquisa}

Uma vez que este estudo procura analisar as percepções de professores no ensino de inglês, este assume um caráter qualitativo-interpretativista de pesquisa, uma vez que a análise se baseia na interpretação de fatores socioculturais e de textos gerados pelos instrumentos de pesquisa, sem se preocupar necessariamente com um número grande de informantes, pois não se trata de uma pesquisa de cunho estatístico.

A pesquisa qualitativa preocupa-se com a compreensão de fenômenos sociais oriundos de um contexto social específico. Nela, o pesquisador procura o entendimento de um processo derivado de certo contexto e de como os indivíduos envolvidos nesse processo o interpretam. Tal contexto pode assumir diferentes formatos, não tendo, portanto, um tamanho definido, podendo variar de acordo com cada situação em análise. Neste trabalho especificamente, o contexto é o ambiente de ensino, pois partimos deste local para interpretar as percepções sobre língua e cultura relacionadas à língua inglesa por parte de um grupo de docentes recémgraduados e em exercício no ensino de inglês.

O paradigma interpretativista visa verificar e entender os significados atribuídos pelo indivíduo a ações e fatores sociais no contexto sociocultural (BORTONI-RICARDO, 2008), já que nenhum dado analisado por si só tem significação, ele precisa ser interpretado. Além disso, por ser uma pesquisa de cunho qualitativo-interpretativista, todo o estudo foi realizado com base nas respostas dadas pelos professores para as perguntas que constituem o questionário e a entrevista utilizados na geração de dados. O questionário constituiu-se de 12 questões abertas de cunho dissertativo para que os informantes pudessem responder abertamente as perguntas, sem que se sentissem limitados no espaço de suas respostas. Além disso, realizaram-se duas entrevistas, uma entrevista grupal e uma individual, porque um dos informantes não pode comparecer à entrevista em grupo. Ambas as entrevistas foram orientadas por um roteiro de 14 perguntas semiestruturadas.

A pesquisa efetivou-se entre 2014 e 2015, contando com um grupo de seis professores egressos do curso de Licenciatura em Letras Português-Inglês da Universidade Tecnológica Federal do Paraná que estavam atuando como docentes de língua inglesa naquele momento. 
Todos os participantes são de nacionalidade brasileira, de classe média / classe média baixa e residiam em Curitiba durante a realização da pesquisa. Dentre estes, 1 é do gênero masculino e 5 são do gênero feminino. Para preservar a identidade de cada um durante a análise os nomes dos participantes foram alterados.

Com a transcrição dos dados das entrevistas e as respostas do questionário, o estudo teve como primordial a interpretação destes textos e, por isso, adotamos a metodologia da análise de conteúdo. Na análise de conteúdo, considera-se que o texto é um meio de expressão e "Um corpus de texto é a representação e a expressão de uma comunidade (...)" (BAUER, 2012, p. 192). Como a finalidade era levantar as percepções de um grupo social tendo como base os textos das entrevistas e do questionário, a análise de conteúdo foi aplicada para codificar e categorizar os dados da pesquisa. Uma segunda metodologia empregada foi a Grounded theory, que permite explorar e gerar conceitos sobre a prática individual ou coletiva em processos sociais com base na verificação de textos ou situações me sala de aula, por exemplo.

\section{As percepções dos docentes sobre língua e cultura: análise}

Na perquirição dos dados obtidos, no que diz respeito às percepções acerca da cultura, as respostas divergiram ao longo dos textos gerados. Dentre as respostas dos participantes, uma primeira visão encontrada foi a de cultura como produção cultural, manifestada em formas diversas, como a culinária, a literatura, a música, o teatro, os feriados nacionais, os jogos, as festas e tradições, etc. Posto isso, pode-se remeter à percepção de cultura como produção artística citada por Eagleton (2005), como podemos ver na resposta de Joaquim, por exemplo, quando ele cita a maneira em que a cultura pode ser abordada nas aulas de língua inglesa. Joaquim ressalta que

há diversas formas. O trabalho com a literatura é sempre válido. Vídeos, textos e músicas são apenas alguns dos exemplos principais. Há também o trabalho com slangs, idiomatic expressions, proverbs, etc. [Q-JOAQUIM, $2014]^{3}$

Nesta resposta encontra-se a percepção da cultura enquanto produção artística de um determinado grupo social representada por músicas, vídeos, textos e, principalmente, pela literatura. Ainda na percepção da cultura enquanto produção artística, os docentes defendem que tais produções são possibilidades de ter contato com a língua/cultura sem estar em contexto de imersão e citam exemplos destas produções, como:

música; [E-MELISSA, 2014]

séries; [E-JOAQUIM, 2014]

teatro; [E-TÁBATA, 2014]

feriados nacionais; [E-MELISSA, 2014]

os jogos; [E-BRENDA, 2014]

\footnotetext{
${ }^{3}$ Nos trechos transcritos das falas dos professores, utilizamos a letra E para indicar que o dado foi retirado das entrevistas e a letra $Q$ para os dados retirados do questionário.
} 
peça teatral... No ensinar... [E-JOAQUIM, 2014]

alguns jogos específicos; [E-MELISSA, 2014]

o modo de vida das pessoas, "n" assuntos. [E-CAMILA, 2014]

Posto isso, na visão do grupo, aqueles elementos produzidos pelo ser humano que são carregados de características socioculturais do contexto social de produção fazem parte destas produções artísticas e, muitas vezes, estes elementos têm como finalidade o entretenimento, como é o caso da música, das séries televisivas, do teatro e dos jogos supracitados, e ainda acabam se configurando como uma imagética característica de um grupo social. No entanto, é possível afirmar que tais exemplos vão além da concepção de uma produção artística, já que, na concepção de Eagleton (2005), a produção cultural enquanto arte parece individualizar estes elementos, como se não fossem frutos de um meio social. Entretanto esta ideia de individualização perante o contexto social não é a apresentada na narrativa dos docentes ao longo da pesquisa.

Uma segunda percepção de cultura encontrada nas respostas dos participantes é aquela que percebe cultura como estereótipos. Quando questionados sobre quais estereótipos vêm à mente de cada um em relação à cultura de língua inglesa, os docentes destacaram:

Ah, eu penso assim, oh, cultural: o britânico toma chá às cinco. Sabe? Esse tipo de coisa. Que tem em livro e comprova que é realmente da cultura deles?! Ou... [E-JOAQUIM, 2014]

Serem polidos demais... [E-MELISSA, 2014]

É! tudo isso. [E-JOAQUIM, 2014]

Pontuais! [E-MELISSA, 2014]

Pontual, direto, muito educado... [E-JOAQUIM, 2014]

$\mathrm{Na}$ fala anterior, Joaquim e Melissa dão exemplos de estereótipos ligados à cultura inglesa que são conhecidos internacionalmente e que acabam adentrando a sala de aula de inglês como sendo uma caracterização de determinado grupo. No entanto, é preciso destacar que os docentes acreditam que a imagem estereotipada pode ser interpretada de várias formas, dependendo da abordagem que se dá a esta. Joaquim ressalta:

não, o único problema é que, eu acho, o termo estereótipo ele é estereotipado negativamente. A gente sempre pensa "ah, é estereótipo, então é coisa ruim". $\mathrm{E}$ às vezes não, às vezes é um padrão, certeza, positivo. [E-JOAQUIM, 2014]

O docente enfatiza que o estereótipo comumente é interpretado de maneira negativa, mas ele acredita que esse poderia ser pensando e abordado positivamente, pois o estereótipo pode remeter a uma possível realidade de um grupo social, mas tudo depende de como o estereótipo será problematizado ou entendido. No entanto, o que interfere nesta questão não é a discussão de o estereótipo ser positivo ou negativo, mas sim a concepção homogeneizante que incorre em uma visão generalizante do Outro. Como afirma Bhabha (2013), o estereótipo decorre do discurso colonialista o qual apresenta uma imagem de fixidez que serve como a representação de uma sociedade, sendo que na maioria das vezes essa imagem é determinada por posições ideológicas que buscam delimitar o espaço de uma nação. O estereótipo seria, 
então, a repetição e fixação de uma ideia determinante ou representante de um grupo social, como por exemplo, aquela de que o inglês é sempre pontual e muito polido. Os estereótipos acabam assumindo uma dualidade: ora podem representar uma forma de olhar e construir sentidos perante uma realidade, ora tornam-se bastante delimitadores, já que os sentidos de uma realidade não são fixos e podem ser ressignificados. Isso porque, independente do contexto, cada sujeito tem sua própria percepção de realidade, podendo um mesmo fato ser percebido de maneiras distintas por cada pessoa. Joaquim afirma que

quanto mais eu vivo, mais eu percebo que o estereótipo tem uma fundamentação do verdadeiro, do real [E-JOAQUIM, 2014]

$\mathrm{Na}$ fala do professor, o estereótipo é fundamentado e não possui neutralidade, uma vez que ele é constituído no âmago de uma sociedade e por isso traz em si carga ideológica do contexto Partindo desta constatação, o estereótipo pode ser entendido como uma "vontade de verdade" ${ }^{4}$ de um grupo social, já que não cabe afirmar que o estereótipo representa a verdade, visto que a verdade em si não existe; e, como afirmaram alguns dos participantes, o estereótipo pode servir como ponto de partida para uma reflexão maior sobre como percebemos o Outro. Sobre isto, Camila se posiciona afirmando:

(...) eu acho que é um ponto a ser refletido, não precisa ser abolido, mas refletido [E-CAMILA, 2014]

Para ela, o estereótipo pode ser utilizado na sala de aula a partir de uma reflexão visando melhor compreender a origem e a ideologia presente neste. Caberia, então, ao professor auxiliar o aluno na reflexão e na compreensão de como tais ideias e imagens são constituídas conforme os discursos que circulam na sociedade. Desenvolver o aluno reflexivo seria uma estratégia para utilizar os estereótipos em sala de aula. Como defende Cíntia:

Eu vejo estereótipos como algo que pode comprometer a ideia do aluno, no sentido de ficar só naquilo, então ele tem uma ideia ou alguém passa essa ideia pra ele e ele não vai além disso. Então, "ah, eu achar que lá nos Estados Unidos todo mundo só come fast food", não necessariamente, pode ter gente que só coma, mas pode ter gente que não come também, então não dá pra generalizar. Acho que essas generalizações de querer colocar os países ou as culturas de um jeito só, elas são perigosas nesse sentido assim, então elas devem ser quebradas por isso, porque é preciso mostrar muito mais que aquilo que tá sendo passado superficialmente, de maneira generalizada, às vezes até de forma pejorativa. Então por isso eu acho que tem que ser quebrado sim, tem que ser mostrado que não é só isso e que tem mais coisa além disso [E-CÍNTIA, 2015]

\footnotetext{
${ }^{4}$ Segundo Foucault, em A Ordem do Discurso, a vontade de verdade é um mecanismo de exclusão, em que a oposição entre o verdadeiro e o falso se dá historicamente dentro de uma instituição, valorizando e repassando o discurso considerado verdadeiro, ou seja, há uma verdade que é defendida pela instituição e esta deve ser passada para o outro, independente dessa "verdade" ser verdadeira ou falsa. Em outras palavras, a vontade de verdade é aquilo em que se acredita.
} 
O que Cíntia propõe é que o estereótipo em si sem ser questionado pode incorrer em uma percepção estagnada, errônea ou mesmo pejorativa daquilo que seria exemplo da cultura do Outro, pois como vimos nos estudos de Kramsch (1998), os estereótipos de um grupo são condicionados por nossa própria cultura de acordo com as ideias que trazemos do Outro a partir de nosso contexto social. Sendo assim, geralmente enxergamos no estereótipo do Outro aquilo que queremos ver e não necessariamente o que realmente seria.

Consoante à noção de estereótipos enquanto frutos de nossa interpretação, temos a percepção da cultura nacional como comunidade imaginada, já que, segundo Hall (2006), a cultura nacional é um discurso através do qual damos sentido a nossa existência enquanto sujeitos. Esse discurso é constituído diacronicamente por meio das histórias, memórias e imagens que compõem a identidade de uma nação, indo além do contexto sociocultural e atingindo o plano da abstração, da imaginação, dando espaço às comunidades imaginadas. Em outras palavras, as comunidades imaginadas são formas de vislumbrar o Outro sem, no entanto, pertencer ou conhecer o Outro realmente. Por isso, muito do que percebemos de outras culturas ou mesmo que reproduzimos enquanto professores de línguas faz parte de nossa imaginação da cultura alheia. No entanto, como disse um dos docentes, a língua é moldada pela cultura, sendo assim, a mudança de uma acarreta a mudança da outra também, logo, nessa mesma lógica, as comunidades imaginadas também não são fixas e podem sofrer transformações ao longo do tempo. Para Cíntia,

Com certeza podemos mudar nossa visão sobre determinada cultura no decorrer do tempo. Dependendo de onde nascemos e vivemos, nossa história de vida, criação dentro de casa, pessoas com que convivemos, o impacto da mídia, entre outros fatores, somos levados a acreditar em certas "verdades". Algumas vezes, essas verdades são baseadas em estereótipos, falta de aprofundamento sobre os assuntos ou até mesmo para provocar reações xenófobas a determinadas culturas e países. A partir do momento que nos dispomos a verificar tais "verdades", pesquisar, olhar mais cuidadosamente, acredito que o conceito da cultura pode assumir um novo sentido. Diferente daquela construção social trazida anteriormente, mas ainda dentro dela, adicionamos uma perspectiva pessoal sobre determinada cultura. Na minha opinião, desde que estejamos aptos a estudar, conhecer e tentar entender, sem julgar como certo e errado, é possível mudar nossa visão sobre determinada cultura. E quanto maior o contato com a cultura, maior a chance de ocorrerem mudanças de perspectiva sobre determinada cultura. [QCÍNTIA, 2014]

Concomitante à mutabilidade da percepção da cultura do outro, voltamo-nos para a concepção pós-moderna na qual a cultura é um fator negociável a cada ato enunciativo e seus significados são transitórios, assim como nossas percepções acerca da situação enunciativa. Ao entrar em contato com pessoas de outra nação, nossa percepção cultural é renegociada e ressignificada. Exemplo disto é ilustrado pela fala de Camila:

Além disso, quando você conhece alguém de um país e cultura diferente da sua, você aprende a respeitar o outro e a entender como a cultura naquele 
lugar funciona, e isso é muito interessante e gratificante, principalmente porque você também pode compartilhar a sua. [Q-CAMILA, 2014]

Camila ressalta a dinamicidade existente entre nossa cultura e a cultura do Outro. Como destaca Bhabha (2013), na construção de sentido entre sujeitos de culturas diferentes existem dois agentes em um terceiro espaço conflituoso negociando o significado de sua interação por meio da linguagem. Assim, o discurso imaginado dos estereótipos é substituído por experiências interativas em diversos contextos, distanciando-se daquilo que seria a "minha cultura" ou a "cultura do outro", dando lugar à "cultura do momento", que, por sua vez, é carregada ideologicamente pelo contexto social. A mudança nem sempre é "radical", já que alguns traços culturais permanecem, pois são reforçados pelos discursos já existentes que se repetem, mas as significações são diferentes a cada situação.

A noção pós-moderna de hibridismo cultural e de terceiro espaço são mais evidentes se considerarmos a língua em uso, principalmente nos casos em que o inglês assume a função de uma língua franca. Sendo a língua algo dinâmico e mutável conforme o contexto de uso, ela é moldada por cada situação interacional. Mais além, considerando língua como cultura, a mutabilidade e a heterogeneidade da linguagem, temos que a cultura segue a mesma lógica, por isso também é mista, volúvel, atemporal, é híbrida. Mesmo nas situações de uso do inglês como uma língua franca, a língua não está livre da ideologia discursiva, visto que traços de nossas crenças e discursos ideológicos são retomados no momento da negociação de sentidos Sobre isso, para Camila, a cultura do Inglês Língua Franca

é uma rede sendo construída... Porque como acho que no contexto de língua franca cada um vem com seu sotaque, suas características e suas culturas acaba se transformando numa rede de microculturas que vai se formando por trás da.../ da língua. [E-CAMILA, 2014]

Por conseguinte, sobre a concepção de língua encontrada no discurso dos docentes, pode-se afirmar que prevalecem traços da visão funcionalista de língua, mas percebe-se principalmente a acepção discursiva da língua. Ainda que não tenham sido questionados diretamente sobre qual a percepção de línguas que os docentes advogam, de maneira geral, pode-se perceber o desapego à noção estruturalista da língua. Em outras palavras, nos dados analisados aqui não encontramos indícios da percepção da língua como um sistema linguístico. Ao contrário, todos os professores parecem defender o entendimento de língua como cultura, isto é, de que língua e cultura são fatores indissociáveis.

Quando a língua é percebida como cultura o que ocorre é o fato de ao abordamos a língua, seja a inglesa ou não, simultaneamente estaremos trabalhando a cultura, tendo em vista que a língua em si é condicionada pelo contexto sociocultural de produção, ou seja, a língua não existe fora de uma determinada cultura. Quando questionados sobre a possível relação entre língua e cultura, todos os docentes defenderam que ambas estão estritamente ligadas, como podemos ver nos excertos a seguir:

Como é sabido, não existe língua sem existir cultura. É o caso do Esperanto, língua inventada, que acabou por não tomar uma proporção mundial por não estar atrelada a nenhum traço cultural. É importante ensinar a cultura de outros países que têm a língua inglesa como idioma oficial, para quebrar o 
estigma de que a língua inglesa só existe no eixo Estados Unidos e Reino Unido. É interessante estudar a cultura, retomar a história de casa país, falar sobre a colonização, como funciona o comércio, os grandes centros e assim, por meio do conhecimento, estabelecer pontos de aproximação e afastamento do aluno comparados à sua rotina. [Q-MELISSA, 2014]

O exemplo anterior reforça o fato de a língua ser condicionada por uma cultura, uma vez que esta é moldada por seus falantes em determinados contextos sociais. Se não houver um contexto, como no caso do Esperanto, uma língua criada fora de um contexto sociocultural como destaca Melissa, o idioma não se estabelece e acaba por desaparecer. Tanto a língua quanto a cultura surgem com um povo e se fortalece no âmago dessa sociedade ao longo dos anos, não pode ser uma simples invenção imposta para um grupo usar. Além disso, quando Melissa afirma ser importante ensinar a cultura de outros países que têm o inglês como idioma oficial, desconstruindo a noção de pertencimento do idioma a países como os Estados Unidos e o Reino Unido, pode-se pensar que o conhecimento da cultura de outros países anglofalantes poderia auxiliar na melhor compreensão de como a língua inglesa se desenvolveu e de como surgem as variantes do inglês nesses diferentes países. Tal ideia seria relevante principalmente para estudantes de inglês como L2, pois estes aprendizes acabam entrando em contato com diversas expressões da língua que são específicas de algumas variantes do inglês - como do inglês britânico ou do inglês australiano - e isso só fará sentido se os alunos tiverem conhecimento daquele contexto; então, conhecer de onde vêm estas expressões, por exemplo, pode facilitar a compreensão da língua. Tábata e Melis sa concordam que o contexto sociocultural é de suma importância na atribuição de sentido à língua, como vemos nas seguintes falas:

é, falar sobre a cultura porque a língua é formada a partir de determinado tipo de raciocínio que tá relacionado à cultura. Então, pra você entender Phrasal verbs, que são palavras de determinado lugar que não tem nada a ver com o sentido literal da palavra, por exemplo, se você não entende a cultura, você não entende como chega naquele phrasal verb. [E-TÁBATA, 2014]

E outra, também, às vezes as pessoas perguntam, principalmente a diferença de pronúncia, né? E lidando com o inglês australiano, por exemplo, por que que o inglês australiano é tão diferente dos outros? (...) Não tem como você universalizar pra onde você é... Daí você vai ver a história do/ da Austrália/ a Austrália é um país que quando foi descoberto é lugar em que a galera mandava os presos da Inglaterra e dos outros países do Reino Unido pra lá, então foi um país formado por:, é, por muitos presos, presos políticos, então o inglês deles, é:, acabou sendo/ não sendo, como se diz?, elitizado, ou enfim, acabou que é um inglês que tem muita gíria, tem muita expressão idiomática, por quê? Porque é diferente do inglês britânico, que nasceu entre aquela realidade dos presos... e é muito legal daí. [E-MELISSA, 2014]

E Melissa completa, afirmando que, 
como já dito anteriormente, essa relação é indissociável. É praticamente impossível ensinar a língua inglesa sem citar, por exemplo, a polidez dos britânicos. Ou o sotaque quase ininteligível dos australianos, um traço totalmente ligado à história da colonização, em que a Austrália servia como uma espécie de terra-de-ninguém, onde eram enviados prisioneiros de guerra. Por se tratar em sua grande maioria de pessoas simples, o inglês ensinado a eles era proferido de forma rudimentar, escapando da pronúncia britânica. Ou seja, toda a formação social de um povo pode ser estudada através da língua. [QMELISSA, 2014]

A colocação inicial de Tábata é interessante e bastante plausível, pois ela afirma ser a língua formada a partir de algum tipo de raciocínio ligado à cultura, ou seja, a língua se constitui em cada situação dentro de um contexto sociocultural e só será inteligível àqueles que compreendem e partilham daquela cultura ou interação. Esta acepção dialoga com a perspectiva discursiva de língua, na qual o sentido é atribuído e estabelecido na interação discursiva em um contexto sociocultural específico. Além disso, Melissa chama a atenção para o fato de a variação da pronúncia da língua inglesa ser frequentemente questionada e lembra que tal diferença geralmente pode ser explicada sócio-historicamente quando se conhecem os valores sócio-históricos, culturais e ideológicos do local originário destas variações. Novamente, a cultura e a língua estão interligadas e, como destacou Melissa, por meio do estudo da língua, é possível conhecer toda a formação social de uma nação.

Em resumo, não só nas falas anteriores, mas também outros momentos do discurso dos docentes, encontramos a percepção de que nosso discurso nos constrói ideologicamente, trazendo em si valores e crenças em que acreditamos, que também resultam de outros discursos. Portanto, de maneira geral, os professores apresentam a percepção de que língua e cultura são conceitos estreitamente ligados e que precisam ser abordados simultaneamente no ensino da língua inglesa, sem que a língua seja compreendida apenas como um conjunto de regras gramaticais e sem que haja a crença de que o ensino de cultura da língua está atrelado ao trabalho com datas comemorativas ou festivais de países cujo inglês é a língua oficial.

\section{Considerações finais}

Como dito inicialmente, este artigo apresenta um panorama com as percepções de um grupo de professores acerca dos conceitos de cultura e de língua no ensino de inglês. Dessa maneira, algumas concepções de cultura foram manifestadas no discurso dos docentes, como a percepção de cultura como produção artística/ cultural, em que os docentes compreendem músicas, filmes, seriados, vídeos e principalmente a literatura como formas de produção de um grupo. Por meio destas produções, os docentes acreditam que o aprendiz possa ter acesso a materiais que ilustram a realidade de uma nação, podendo facilitar a assimilação da língua e da cultura-alvo mesmo que o aprendiz não esteja em um contexto de imersão. Além disso, a produção cultural seria uma forma de diferenciação entre culturas e seria constituinte da identidade de um povo.

Outra compreensão da cultura presente na fala dos docentes é aquela em que esta é percebida enquanto estereótipos. Os docentes destacaram que muitos alunos já trazem uma ideia pré-concebida da cultura-alvo e reforçaram que os estereótipos não precisam ser 
evitados no ensino da língua inglesa, mas sim problematizados e refletidos. Concomitante à percepção do estereótipo, a visão de cultura como comunidades imaginadas foi constatada na fala dos professores, pois assumem que muito do que sabemos ou pensamos sobre o Outro é criado por nossa imaginação ou nossa percepção a partir de uma posição fora do contexto social do Outro. Por fim, apareceu também a noção de que a cultura, assim como a língua, não é algo fixo, estável e imutável, pois, como afirmaram os docentes, ela se modifica a cada contexto de interação, sendo negociada e ressignificada por cada sujeito por meio da língua e conforme a situação. Além disso, os professores parecem concordar que a língua e a cultura ocorrem simultaneamente na prática discursiva assim como no ensino da língua inglesa ou de qualquer língua, pois são fatores que se complementam na interação social.

Enfim, as percepções trazidas neste estudo são exemplos de como esses dois termos língua e cultura - estão sendo compreendidos no ensino da língua inglesa num cenário atual, ainda que parte dessas percepções possa ter mudado e sido ressignificada, pois as representações dos sujeitos passam por constante transformação, assim como a língua e a cultura, conforme vimos ao longo deste artigo.

\section{Referências}

BAKHTIN, M. (Volochinov). Marxismo e filosofia da linguagem. 7. ed. São Paulo: Editora Hucitec, 1995.

BAUER, M. Análise de conteúdo clássica: uma revisão. In: BAUER, M.; GASKELL,G. [Orgs.]. Pesquisa qualitativa com texto, imagem e som: um manual prático. [Tradução de Pedrinho A. Guareschi]. 10. ed. Petrópolis, RJ: Vozes, 2012.

BHABHA, H. K. O local da cultura. [Tradução Myriam Ávila, Eliana Lourenço de Lima Reis, Gláucia Renate Gonçalves]. 2. ed. Belo Horizonte: Editora UFMG, 2013.

BORTONI-RICARDO, S. M. O professor pesquisador: Introdução à pesquisa qualitativa. 1 . Ed. São Paulo: Parábola Editorial, 2008.

EAGLETON, T. A ideia de cultura. [Tradução de Sandra Castello Branco]. São Paulo: Editora UNESP, 2005.

HALL, S. A identidade cultural na pós-modernidade. [Tradução Tomaz Tadeu da Silva, Guaracira Lopes Louro]. 11. ed. Rio de Janeiro: DP\&A, 2006.

Da diaspora: identidades e mediações culturais. [Tradução Adelaide La Guardia Resende]. 2. ed. Belo Horizonte: Editora UFMG, 2013.

JORDÃO, C. M. (2006). O Ensino de Línguas Estrangeiras: de código a discurso. In: VAZ BONI, V. Tendências Contemporâneas no Ensino de Línguas. União da Vitória: Kaygangue.

KRAMSCH, C. Context and culture in language teaching. UK: Oxford University. Press, 1993. 
Language and culture. UK: Oxford University Press, 1998.

SILVA, G. dos S. da. Representações culturais por docentes de língua inglesa: um paralelo entre representações, língua inglesa e cultura. 2016. 145 f. Dissertação (Mestrado em Letras) - Pós-graduação em Letras, Universidade Federal do Paraná, Curitiba, 2016.

THORNBERG, R. Grounded theory. In: ARTHUR et al. (orgs). Research methods \& methodologies in education. London: SAGE Publications, 2012.

WILLIAMS, R. Cultura. Rio de Janeiro: Paz e Terra, 1992. 